\title{
The effect of carvedilol and propranolol on portal hypertension in patients with cirrhosis: a meta-analysis
}

This article was published in the following Dove Press journal:

Patient Preference and Adherence

14 July 2015

Number of times this article has been viewed

\author{
Sheng Chen ${ }^{1, *}$ \\ Jin-Jun Wang ${ }^{2, *}$ \\ Qin-Qin Wang' \\ Jun-Wei Hu' \\ Shuang Dong' \\ Li-Juan $\mathrm{Hu}^{\prime}$ \\ Yi-Cheng Jian' \\ Xin-Yan Liu ${ }^{2}$ \\ Gen-Mei Yang ${ }^{2}$ \\ Wu-Jun Xiong ${ }^{\prime}$ \\ 'Department of Hepatology, Tongji \\ University School of Medicine, \\ Shanghai East Hospital, ${ }^{2}$ Department \\ of Gerontology, Shanghai Traditional \\ Chinese Medicine University, Shanghai \\ Putuo Central Hospital, Shanghai, \\ People's Republic of China \\ *These authors contributed equally \\ to this work
}

Correspondence: Wu-Jun Xiong Department of Hepatology, Tongji University School of Medicine, Shanghai East Hospital, Shanghai 200I20, People's Republic of China Email xxxiongwj@I63.com
Purpose: Several randomized controlled clinical trials have been conducted to investigate the role of carvedilol and propranolol on the effect of portal pressure in patients with cirrhosis, leading to controversial results. Current meta-analysis was performed to compare the efficacy of the two drugs on portal pressure.

Patients and methods: Two-hundred and ninety eligible patients were recruited. Published studies were selected based on PubMed, the Cochrane Library, Chinese Journal Full-text Database, and Wanfang Database. The outcome measurements included the mean difference (MD) in the percentage of hepatic vein pressure gradient reduction (\%HVPG reduction), the risk ratio (RR) of nonresponders in hemodynamic assessment, and the percentage of mean arterial pressure reduction (\%MAP reduction). Subgroup analysis was performed.

Results: Seven trials were identified (including five acute and three long-term drug administration randomized controlled trials). A summary of pooled MD between the $\% \mathrm{HVPG}$ reduction is as follows: overall -8.62 (confidence interval [CI] $-11.76,-5.48, P<0.00001$ ), acute -10.05 (CI $-14.24,-5.86, P<0.00001$ ), and long term -6.80 (CI $-11.53,-2.07, P=0.005$ ), while summary of pooled RR of hemodynamic nonresponders with carvedilol was as follows: overall 0.64 (CI $0.51,0.81, P=0.0002$ ), acute 0.63 (CI 0.47, 0.85, $P=0.002$ ), and long term 0.67 (CI 0.47, $0.97, P=0.03$ ). Both of the outcome measurements favored carvedilol. Significant heterogeneity $\left(P<0.1, I^{2}=92 \%\right)$ existed between the two treatment groups in \%MAP reduction. No considerable difference could be observed in the \%MAP reduction through the poor overlapping CI boundaries.

Conclusion: Carvedilol has a greater portal hypertensive effect than propranolol. Further comparative trials of the two drugs are required to identify the effect of MAP reduction.

Keywords: carvedilol, propranolol, portal hypertension, randomized controlled clinical trials, meta-analysis

\section{Introduction}

It has already been acknowledged that portal hypertension is an unavoidable complication of cirrhosis, and variceal bleeding is the most serious consequence, resulting in a significant mortality of $7 \%-15 \% .{ }^{1-3}$ Hepatic vein pressure gradient (HVPG) is regarded as the gold standard for the assessment of treatment effects of portal hypertension. Measurement of HVPG can accurately reflect the pressure in patients with portal hypertension. ${ }^{4}$ It has been shown that the HVPG should increase to above $12 \mathrm{mmHg}$ for variceal bleeding. ${ }^{5}$ A good hemodynamic response is defined as the reduction of HVPG to a value $<12 \mathrm{mmHg}$ or by $\geq 20 \%$ from baseline, which can significantly decrease the risk of bleeding or mortality, presenting a better outcome than hemodynamic nonresponders. ${ }^{6,7}$ 
The nonselective beta-blockers (especially propranolol and nadolol) or the endoscopic variceal ligation (EVL) is currently recommended as the first-line therapy to prevent variceal bleeding. ${ }^{8,9}$ However, only a few patients show a substantial HVPG reduction after propranolol administration. When it comes to EVL, its invasiveness and costs have resulted in variable application. Carvedilol, having been proposed to be used in clinical practice in recent years, is a promising nonselective beta-blocker with intrinsic anti-alpha1 adrenergic activity (one-tenth of its beta-blocker activity), ${ }^{10}$ giving the drug a potential for a higher portal pressure reduction compared to propranolol. There have been several randomized controlled clinical trials exploring the efficacy of carvedilol and propranolol in patients with portal hypertension, yielding controversial results.

The aim of the present meta-analysis was to assess the hemodynamic effectiveness of carvedilol and propranolol on the effect of portal hypertension in patients with cirrhosis. We have made extensive efforts to find all relevant studies by means of computerized and manual search, and the treatment effect is combined across all studies.

\section{Methods \\ Data retrieval}

Pertinent studies were retrieved between January 1995 and December 2013 in the Pubmed, The Cochrane Library, Chinese Journal Full-text Database, and Wanfang Database with the keywords carvedilol, propranolol, portal hypertension, randomized controlled clinical trials in both English (from the index Medicus Medical Subject Headings list) and Chinese. A manual search of the reference lists of pertinent studies was also performed. When the results of a single study were reported in more than one publication, only the most recent and complete data were included. Unpublished studies were not referred to in this meta-analysis.

\section{Inclusion and exclusion criteria}

To be included in this meta-analysis, a study had to meet the following criteria. 1) The published study was randomized controlled trial (RCT). 2) The percentage of HPVG reduction (\%HVPG reduction) was a main outcome measure of the treatment effect. Secondary outcome measures included number of responders in hemodynamic evaluation and the percentage of mean arterial pressure reduction (\%MAP reduction). 3) The participants were patients with clinically significant portal hypertension. Randomized trials were included irrespective of blinding or language.
The criteria for the selection of a study were established before this meta-analysis was designed.

\section{Data collection}

Data were extracted by two independent authors (Liu and Yang), and disagreements were solved by discussion. For each study, the following data were extracted: 1) patients' characteristics, including number of patients, mean age, sex, etiology of cirrhosis, Child-Pugh score, and proportion of patients with previous variceal bleeding and 2) outcome measures, including the \%HVPG reduction, the number of hemodynamic responders, and the \%MAP reduction.

\section{Outcome measures}

The main outcome measure was $\%$ HVPG reduction; secondary outcome measures included the number of patients achieving a hemodynamic response and the outcome related to main adverse events, such as \%MAP reduction.

\section{Statistical analysis}

Studies and patient characteristics were reported as number of observations, proportions, or means \pm standard deviations.

Analyses were performed by fixed-effects model and RevMan software (Cochrane Collaboration, Canada, Version 5.2.7). Inverse variance was used to calculate the mean difference (MD) of the $\% \mathrm{HVPG}$ reduction and the \%MAP reduction. The Mantel-Haenszel was used to assess the hemodynamic responders using the risk ratio (RR). Statistical data were expressed as $95 \%$ confidence interval (CI). A level of $P<0.05$ was considered statistically significant. Adverse effect of the meta-analysis was performed by random-effects model.

Heterogeneity was evaluated by a chi-square test and was reported using $I^{2}$ values. If pronounced heterogeneity was found, potential reasons were explored and the combinability of trials was reconsidered. The significant level for heterogeneity test was $P=0.1$. Methodological quality assessment was conducted using a validated table derived from the Cochrane Handbook, version 5.1.0, and Fisher's exact probability test was conducted to calculate the difference levels between qualitative variables. The studies might be measured by acute and long-term hemodynamic effects under clinical treatment, so subgroup analysis was implemented. However, if the combinability of trials was inappropriate, separate analysis was also undertaken.

Analyses were conducted following the intention-to-treat principle and included all patients randomized as they were reported in each single trial. 


\section{Results}

\section{Analysis of retrieval results}

Overall, 44 pertinent studies were identified. Thirty-one were excluded by reading the abstract because they did not include randomized clinical trials. The remaining eleven were RCTs and were assessed for inclusion in the present meta-analysis (Figure 1).

Among these eleven, three were excluded as they did not compare carvedilol with propranolol and did not include hemodynamic measurements; ${ }^{11-13}$ another randomized controlled trial incorporated the HVPG as a main measurement ${ }^{14}$ but was excluded because the \%HVPG reduction was given in a way that made it difficult to assess the pooled effect using current software. The remaining seven studies ${ }^{15-21}$ corresponded to our inclusion criteria and were included in the present study. All included studies had been published. The characteristics of them are summarized in Table 1. Among the seven, four ${ }^{15,18}$ assessed the acute hemodynamic effect and two ${ }^{16,19}$ evaluated the long-term effect. In one ${ }^{17}$ study, both the acute hemodynamic and long-term effects were assessed after initial trial drug administration. As a result, five acute and three long-term RCTs were available for the present meta-analysis.

A total of 290 eligible patients were recruited in the seven trials, 145 in the carvedilol group and 145 in the propranolol group. The characteristics of patients in the seven studies are summarized in Table 2, and none of the parameters differed significantly between the two groups across the seven studies.

\section{Methodological quality assessment}

Methodological quality of each selected RCT was assessed in terms of the following six domains ${ }^{22,23}$ 1) random sequence generation; 2) allocation concealment; 3) blinding of participants and personnel; 4) blinding of outcome assessment; 5) incomplete outcome data; and 6) selective reporting. The quality of seven studies included was relatively unsatisfactory (Table 3). The risk of bias is summarized in Figure 2.

\section{Meta-analysis \\ Main outcome \\ \%HVPG reduction}

Mean baseline HVPG was $16.4 \mathrm{mmHg}$ (median $16.6 \mathrm{mmHg}$ ) in the propranolol-treated group and $16.8 \mathrm{mmHg}$ (median $18.9 \mathrm{mmHg}$ ) in the carvedilol-treated group. The mean $\%$ HVPG reduction was $12.5 \%$ (median $12.4 \%$ ) with propranolol and $23.9 \%$ (median 26.4\%) with carvedilol (including patients with both acute and long-term assessments) (Table 4).

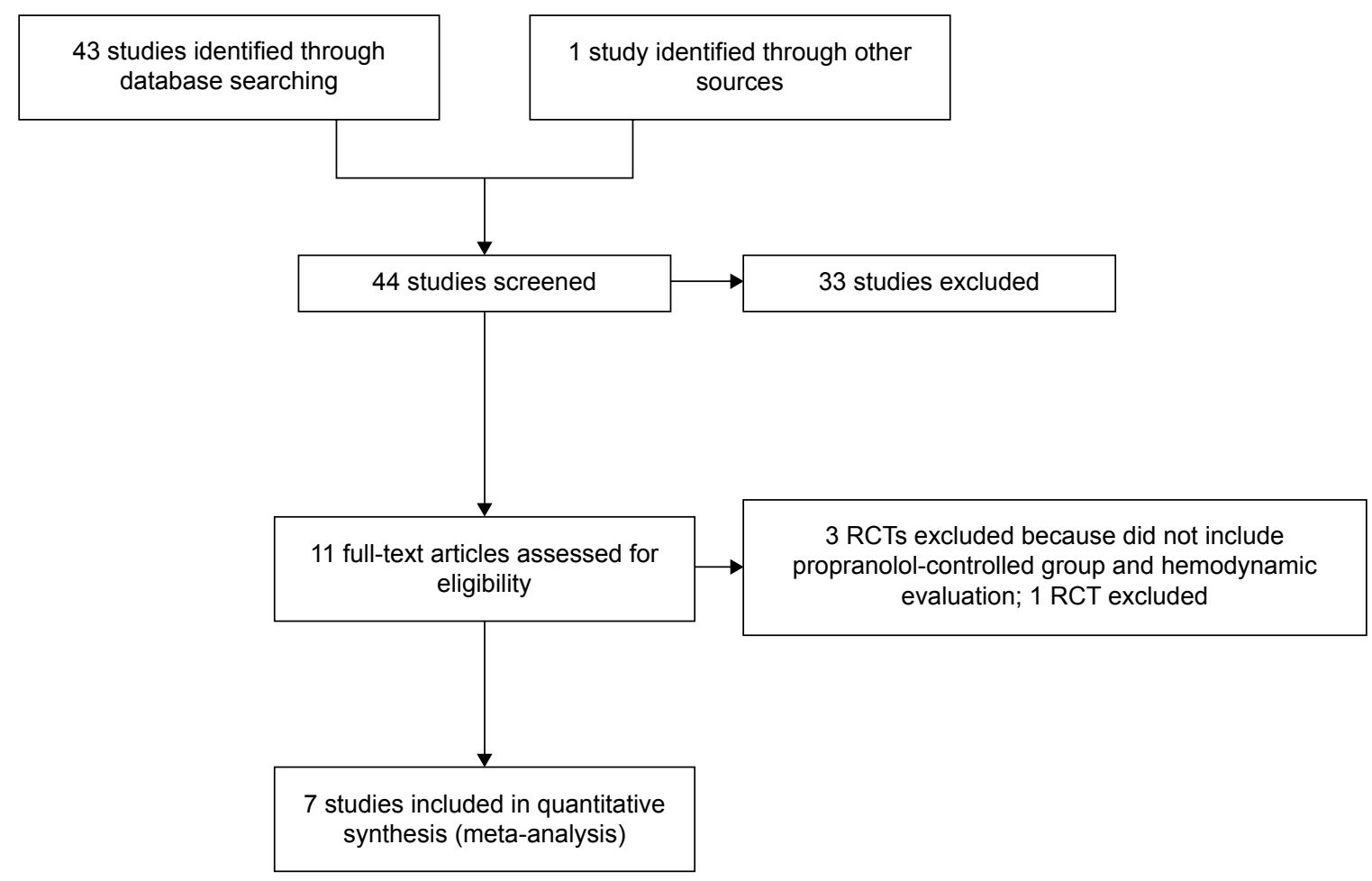

Figure I Study flow diagram of the identification process of RCTs for inclusion in this meta-analysis. Abbreviation: RCTs, randomized controlled trials. 
Table I Characteristics of seven included studies

\begin{tabular}{|c|c|c|c|c|c|c|c|}
\hline \multirow[t]{2}{*}{$\begin{array}{l}\text { First } \\
\text { author }\end{array}$} & \multirow[t]{2}{*}{$\begin{array}{l}\text { Publication } \\
\text { year }\end{array}$} & \multirow[t]{2}{*}{$\begin{array}{l}\text { Study } \\
\text { design }\end{array}$} & \multirow[t]{2}{*}{$\begin{array}{l}\text { Sample } \\
\text { size }\end{array}$} & \multirow[t]{2}{*}{$\begin{array}{l}\text { No of } \\
\text { patients C/P }\end{array}$} & \multirow[t]{2}{*}{$\begin{array}{l}\text { Time of outcome } \\
\text { assessment }\end{array}$} & \multicolumn{2}{|c|}{$\begin{array}{l}\text { No of patients } \\
\text { with first/ } \\
\text { second HVPG } \\
\text { measurement }\end{array}$} \\
\hline & & & & & & C & $\mathbf{P}$ \\
\hline Bañares et al $\left.\right|^{15}$ & 1999 & RCT & 28 & $14 / 14$ & Acute & $14 / 14$ & $14 / 14$ \\
\hline Lin et $\mathrm{a}^{18}$ & 2004 & RCT & 22 & $11 / 11$ & Acute & $|1 /| \mid$ & $11 / 11$ \\
\hline $\operatorname{Ren}^{20}$ & 2012 & $\mathrm{RCT}$ & 61 & $30 / 31$ & Acute & $30 / 30$ & $3|/ 3|$ \\
\hline $\mathrm{Qu}^{21}$ & 2012 & $\mathrm{RCT}$ & 54 & $25 / 29$ & Acute & $25 / 25$ & $29 / 29$ \\
\hline \multirow[t]{2}{*}{ De et $\mathrm{a}^{17}$} & 2002 & $\mathrm{RCT}$ & 36 & $18 / 18$ & Acute & $18 / 18$ & $18 / 18$ \\
\hline & & & & & Long-term & $18 / 17$ & $18 / 16$ \\
\hline Bañares et $\mathrm{al}^{16}$ & 2002 & $\mathrm{RCT}$ & 51 & $26 / 25$ & Long-term & $26 / 24$ & $25 / 22$ \\
\hline Hobolth et al ${ }^{19}$ & 2012 & $\mathrm{RCT}$ & 38 & $21 / 17$ & Long-term & $2|/ 2|$ & $17 / 17$ \\
\hline
\end{tabular}

Abbreviations: No, number; C, carvedilol; P, propranolol; HVPG, hepatic vein pressure gradient; RCT, randomized controlled trial.

Table 2 Characteristics of patients in seven included studies

\begin{tabular}{|c|c|c|c|c|c|c|c|}
\hline & $\begin{array}{l}\text { Treatment } \\
\text { group }\end{array}$ & $\begin{array}{l}\text { Patients } \\
\text { (N) }\end{array}$ & $\begin{array}{l}\text { Age } \\
(\text { mean } \pm \text { SD })\end{array}$ & $\begin{array}{l}\text { Males } \\
(\mathbf{N})\end{array}$ & $\begin{array}{l}\text { Alcoholic/viral } \\
\text { etiology }(\mathbf{N})\end{array}$ & $\begin{array}{l}\text { Child-Pugh } \\
\text { class } A / B / C(N)\end{array}$ & $\begin{array}{l}\text { Previous varicea } \\
\text { bleeding }(\mathbf{N})\end{array}$ \\
\hline \multirow[t]{2}{*}{ Bañares et al ${ }^{15}$} & C & 14 & $54.6 \pm 8.8$ & NM & $8 / \mathrm{NM}$ & $8 / 4 / 2$ & 9 \\
\hline & $P$ & 14 & $51.4 \pm 8.5$ & NM & $8 / N M$ & $5 / 6 / 3$ & 9 \\
\hline \multirow[t]{2}{*}{ Lin et $\mathrm{al}^{18}$} & C & 11 & $59 \pm 13.3$ & 8 & $0 / 11$ & $8.7 \pm 3.0^{\mathrm{a}}$ & NM \\
\hline & $P$ & 11 & $61 \pm 13.3$ & 9 & $0 / 11$ & $7.3 \pm 2.7^{a}$ & NM \\
\hline \multirow[t]{2}{*}{$\operatorname{Ren}^{20}$} & C & 30 & $50.12 \pm 9.28$ & 23 & $3 / 9$ & $16 / 12 / 2$ & 15 \\
\hline & $\mathrm{P}$ & 31 & $52.93 \pm 13.06$ & 21 & $2 / 21$ & $22 / 7 / 2$ & 18 \\
\hline \multirow[t]{2}{*}{$\mathrm{Qu}^{21}$} & C & 25 & $48.4 \pm 9.8$ & 20 & $1 / 18$ & $12 / 13 / 1$ & 14 \\
\hline & $P$ & 29 & $53.7 \pm 12.9$ & 20 & $3 / 17$ & $9 / 17 / 2$ & 16 \\
\hline \multirow[t]{2}{*}{ De et $\mathrm{al}^{17}$} & C & 18 & $42.3 \pm 11.9$ & 15 & $5 / 9$ & $5 / 9 / 4$ & 7 \\
\hline & $P$ & 18 & $47.3 \pm 12.9$ & 17 & $10 / 5$ & $0 / 13 / 5$ & 7 \\
\hline \multirow[t]{2}{*}{ Bañares et al ${ }^{16}$} & C & 26 & $57.9 \pm 7.6$ & 19 & $6 / 18$ & $13 / 10 / 3$ & 0 \\
\hline & $P$ & 25 & $58.4 \pm I I$ & 15 & $9 / 16$ & $15 / 6 / 4$ & 0 \\
\hline \multirow[t]{2}{*}{ Hobolth et al ${ }^{19}$} & C & 21 & $58.2 \pm 6.8$ & 12 & $2 / 18$ & $8 / 7 / 6$ & 5 \\
\hline & $\mathrm{P}$ & 17 & $56.2 \pm 6.1$ & 12 & $|2 /|$ & $6 / 6 / 4$ & 5 \\
\hline
\end{tabular}

Note: a Child-Pugh score, mean \pm SD (derived from the standard error reported in the study).

Abbreviations: N, number; SD, standard deviation; C, carvedilol; NM, not mentioned; P, propranolol.

Table 3 Methodological quality assessment of included studies

\begin{tabular}{|c|c|c|c|c|c|c|}
\hline & $\begin{array}{l}\text { Random sequence } \\
\text { generation }\end{array}$ & $\begin{array}{l}\text { Allocation } \\
\text { concealment }\end{array}$ & $\begin{array}{l}\text { Blinding of participants } \\
\text { and personnel }\end{array}$ & $\begin{array}{l}\text { Blinding of outcome } \\
\text { assessment }\end{array}$ & $\begin{array}{l}\text { Incomplete } \\
\text { outcome data }\end{array}$ & $\begin{array}{l}\text { Selective } \\
\text { reporting }\end{array}$ \\
\hline Bañares et $\mathrm{al}^{15}$ & Unclear risk & Unclear risk & Low risk & Low risk & Low risk & Low risk \\
\hline Bañares et al ${ }^{16}$ & Low risk & Low risk & Low risk & Low risk & Low risk & Low risk \\
\hline De et al ${ }^{17}$ (acute) & Low risk & Low risk & Low risk & Low risk & Low risk & Low risk \\
\hline De et al ${ }^{17}$ (long-term) & Low risk & Low risk & Low risk & Low risk & Low risk & Low risk \\
\hline Hobolth et $\mathrm{al}^{14}$ & Unclear risk & Low risk & Low risk & Low risk & Low risk & Low risk \\
\hline Lin et $\mathrm{al}^{18}$ & Low risk & Unclear risk & Unclear risk & Unclear risk & Low risk & High risk \\
\hline $\operatorname{Ren}^{20}$ & Low risk & High risk & High risk & High risk & Low risk & Low risk \\
\hline $\mathrm{Qu}^{2 !}$ & Low risk & High risk & High risk & High risk & Low risk & Low risk \\
\hline
\end{tabular}




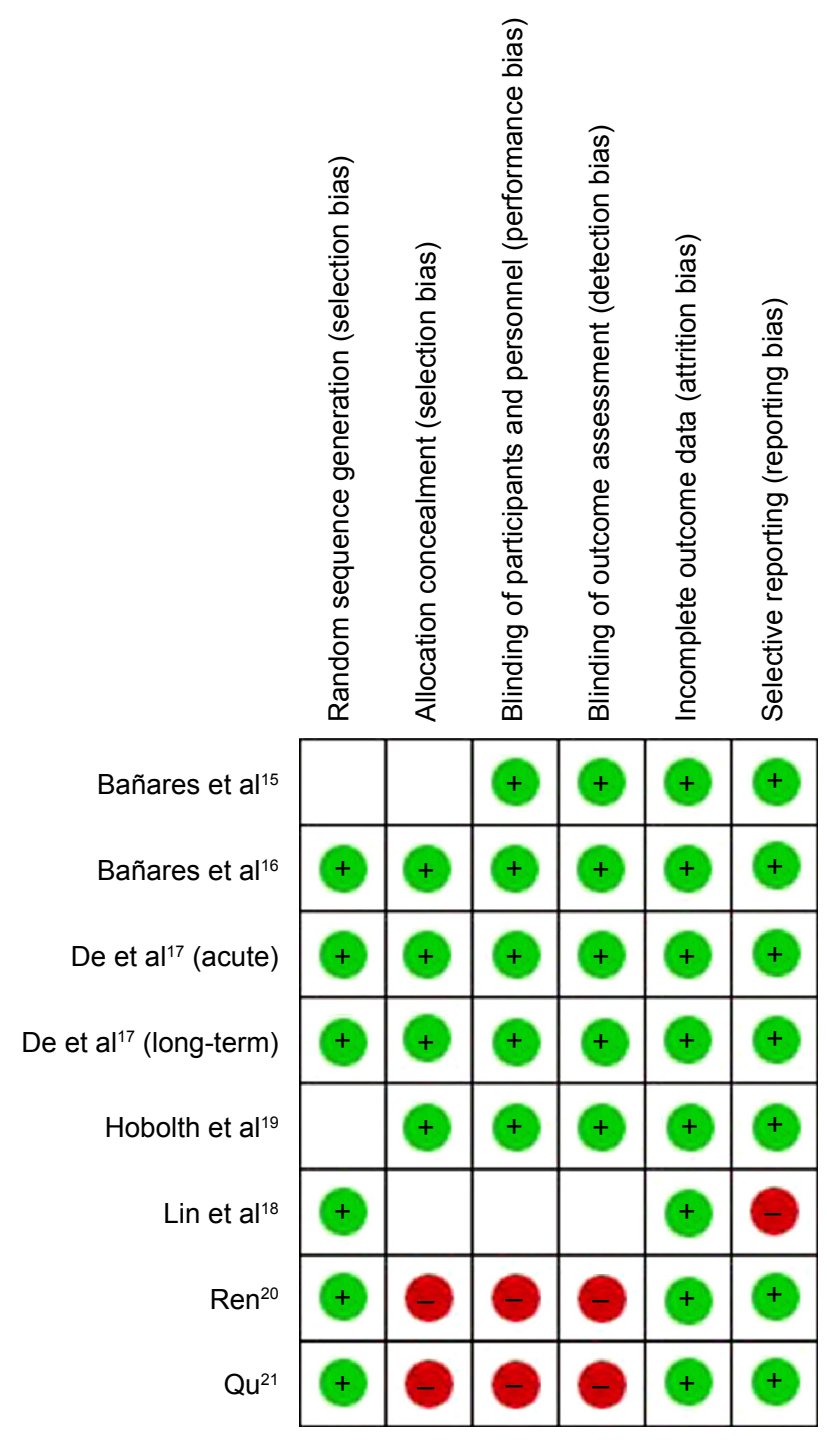

Figure 2 Risk of bias summary. Green dot, low risk; red dot, high risk; empty cell, unclear risk.
The pooled MD \%HVPG reductions with the two drugs was -8.62 (CI $-11.76,-5.48$; fixed-effect model), denoting superiority of carvedilol $(Z=5.38, P<0.00001)$ (Figure 3$)$. No heterogeneity was found $\left(P=0.46 ; I^{2}=0 \%\right)$.

A sensitivity analysis demonstrated that \%HVPG reduction is significantly higher in carvedilol-treated group for either the acute or the long-term treatment (Figure 3) and superiority of carvedilol hold true by excluding the studies ${ }^{18}$ with high-risk factors (MD -7.1, CI -10.64, -3.56; fixedeffect model) (Figure 4).

\section{Secondary outcome}

\section{Number of hemodynamic responders}

The total number of hemodynamic responders was 55 out of 147 evaluable patients in propranolol as compared to 89 out of 149 with carvedilol (including patients with both acute and long-term assessments) (Table 4).

The pooled RR of hemodynamic nonresponse with carvedilol was 0.64 (CI 0.51-0.81; fixed-effect model), underlining superiority of carvedilol in responder rate $(Z=3.71, P=0.0002)$. No heterogeneity was found $\left(P=0.83 ; P^{2}=0 \%\right.$ ) (Figure 5 ).

A sensitivity analysis suggested that responder rate is significantly higher in carvedilol-treated group with either the acute or the long-term treatment (Figure 5) and superiority of carvedilol hold true by excluding the studies ${ }^{18}$ with high-risk factors (RR 0.63, CI 0.47, 0.85; fixed-effect model) (Figure 6).

\section{Adverse event \%MAP reduction}

The test of heterogeneity $\left(P<0.00001, I^{2}=94 \%\right.$, randomeffect model) for the reduction of \%MAP (Table 5) in all

Table 4 Main results of the included studies

\begin{tabular}{|c|c|c|c|c|c|c|c|}
\hline & \multirow{2}{*}{$\begin{array}{l}\text { Time of } \\
\text { outcome } \\
\text { assessment }\end{array}$} & \multicolumn{3}{|l|}{ Carvedilol } & \multicolumn{3}{|l|}{ Propranolol } \\
\hline & & $\begin{array}{l}\text { HVPG } \\
\text { baseline, } \mathrm{mmHg} \\
\left(\text { mean } \pm \mathbf{S D}^{\mathrm{a}}\right)\end{array}$ & $\begin{array}{l}\% \text { HVPG } \\
\text { reduction } \\
\left(\text { mean } \pm \mathbf{S D}^{\mathrm{a}}\right)\end{array}$ & $\begin{array}{l}\text { Hemodynamic } \\
\text { responders }^{b} \\
(\mathrm{n} / \mathrm{N})\end{array}$ & $\begin{array}{l}\text { HVPG baseline, } \\
\text { mmHg } \\
\left(\operatorname{mean} \pm \mathrm{SD}^{\mathrm{a}}\right)\end{array}$ & $\begin{array}{l}\% \text { HVPG } \\
\text { reduction } \\
\left(\text { mean } \pm \mathbf{S D}^{\mathrm{a}}\right)\end{array}$ & $\begin{array}{l}\text { Hemodynamic } \\
\text { responders }^{b} \\
(\mathrm{n} / \mathrm{N})\end{array}$ \\
\hline Bañares et $\mathrm{al}^{15}$ & Acute & $19.5 \pm 4.9$ & $20.4 \pm 7.5$ & $9 / 14$ & $20.4 \pm 4.1$ & $12.7 \pm 7.48$ & $2 / 14$ \\
\hline Lin et $\mathrm{a}^{18}$ & Acute & $18.9 \pm 6.0$ & $18.6 \pm 11.9$ & NM & $17.6 \pm 4.0$ & $10.1 \pm 11.9$ & NM \\
\hline $\operatorname{Ren}^{20}$ & Acute & $12.87 \pm 3.32$ & $28.30 \pm 22.19$ & $17 / 30$ & $13.57 \pm 5.79$ & $12.38 \pm 24.09$ & $|3 / 3|$ \\
\hline $\mathrm{Qu}^{21}$ & Acute & $12.89 \pm 3.27$ & $26.43 \pm 22.77$ & $15 / 25$ & $12.88 \pm 5.17$ & $1.45 \pm 34.58$ & $9 / 29$ \\
\hline \multirow[t]{2}{*}{ De et al ${ }^{17}$} & Acute & $19.0 \pm 3.8$ & $27.7 \pm 31.5$ & $11 / 18$ & $16.60 \pm 3.9$ & $22.9 \pm 27.4$ & $9 / 18$ \\
\hline & Long-term & $19.0 \pm 3.8$ & $27.7 \pm 31.5$ & $11 / 18$ & $16.60 \pm 4.0$ & $22.98 \pm 20.1$ & $10 / 16$ \\
\hline Bañares et $\mathrm{al}^{16}$ & Long-term & $19.1 \pm 5.4$ & $19 \pm 9.8$ & $13 / 24$ & $20.3 \pm 4.2$ & $12 \pm 9.4$ & $5 / 22$ \\
\hline Hobolth et al ${ }^{19}$ & Long-term & $17.6 \pm 4.2$ & $19.3 \pm 16.1$ & $|3 / 2|$ & $18.4 \pm 3.6$ & $12.5 \pm 16.7$ & $7 / 17$ \\
\hline
\end{tabular}

Notes: aSD: in the studies by Bañares et al ${ }^{15,16}$ and by Lin et al ${ }^{18}$ the standard deviation of the mean was derived from the standard error of mean reported in the original studies. 'bemodynamic responders were defined as patients whose HVPG reduction was $\geq 20 \%$ of baseline or $\leq 12 \mathrm{mmHg}$.

Abbreviations: HVPG, hepatic vein pressure gradient; SD, standard deviation; n/N, number; NM, not mentioned. 


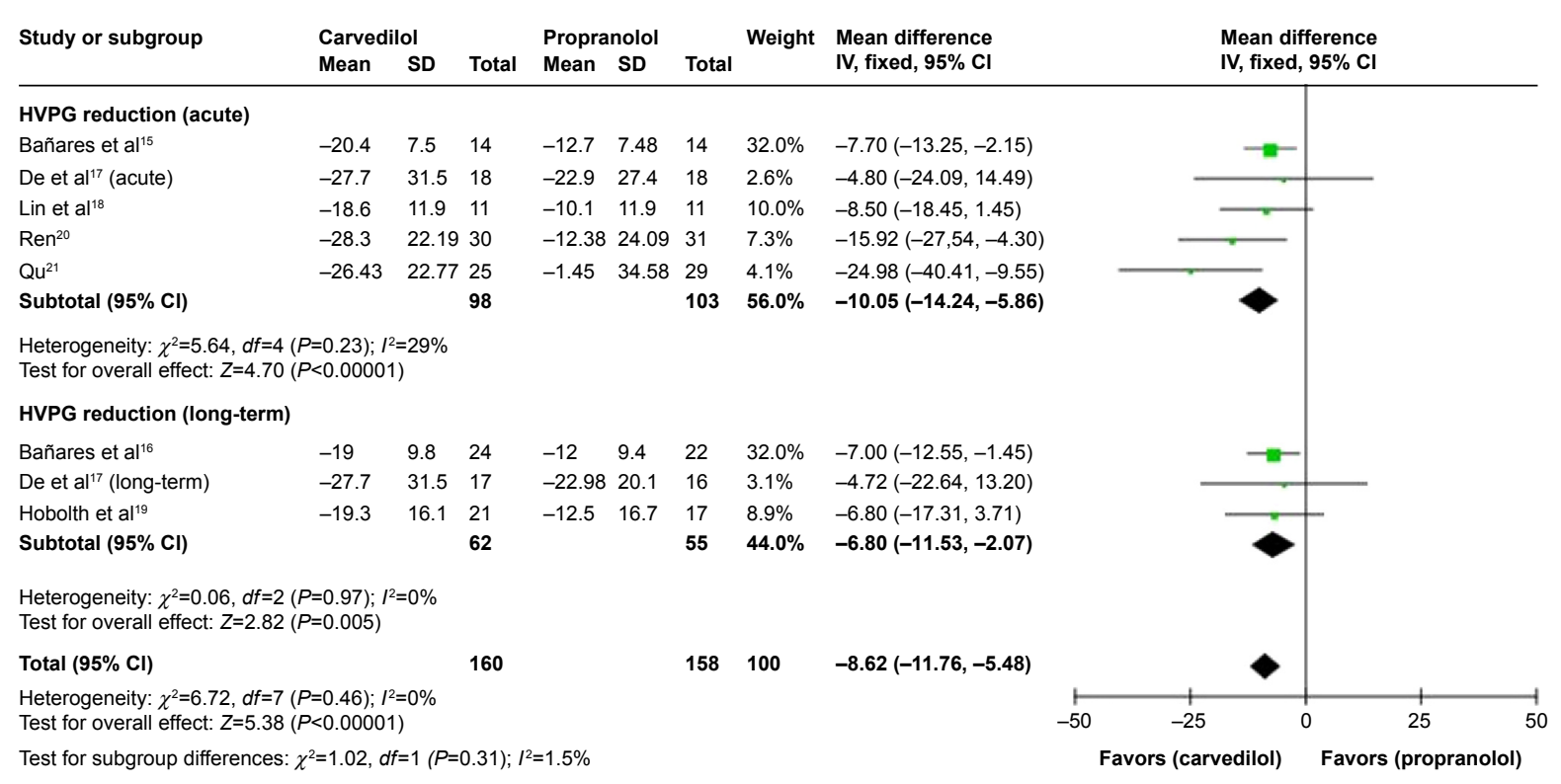

Figure 3 Subgroup analysis (fixed-effect model) of the percentage of hepatic vein pressure gradient reduction, representing the MDs (rectangles) and $95 \% \mathrm{Cl}$ (horizontal lines) for trials that compared carvedilol and propranolol.

Notes: The size of the rectangles indicates the weight of every trial. The above diamond shows the subtotal MD and $95 \% \mathrm{Cl}$ of the acute drug administration. The below diamond shows the subtotal MD and $95 \% \mathrm{Cl}$ of the long-term drug administration. The heterogeneity test is also performed.

Abbreviations: MD, mean difference; $\mathrm{Cl}$, confidence interval; SD, standard deviation; IV, inverse variance; HVPG, hepatic vein pressure gradient.

studies indicated that important differences might exist. But when considering the subgroups separately, heterogeneity was significant, precluding combining the results of two drugs in \%MAP reduction (Figure 7).

However, in the acute assessment, if we exclude one study ${ }^{15}$ with unclear risk, the heterogeneity would be eliminated $(P=0.66$, $P^{2}=0 \%$ ), favoring carvedilol in decreasing MAP over propranolol (MD -2.80, CI -4.72, -0.89) (Figure 8). Nevertheless, the remaining three studies estimated were all high-risk trials. Therefore, this result should be considered with caution.

\section{Discussion}

Propranolol has been utilized for the prevention of variceal bleeding in cirrhotic patients with portal hypertension for almost 30 years. $^{24}$ Recently, carvedilol, which causes beta-blockade as well as anti-alphal adrenergic activities,

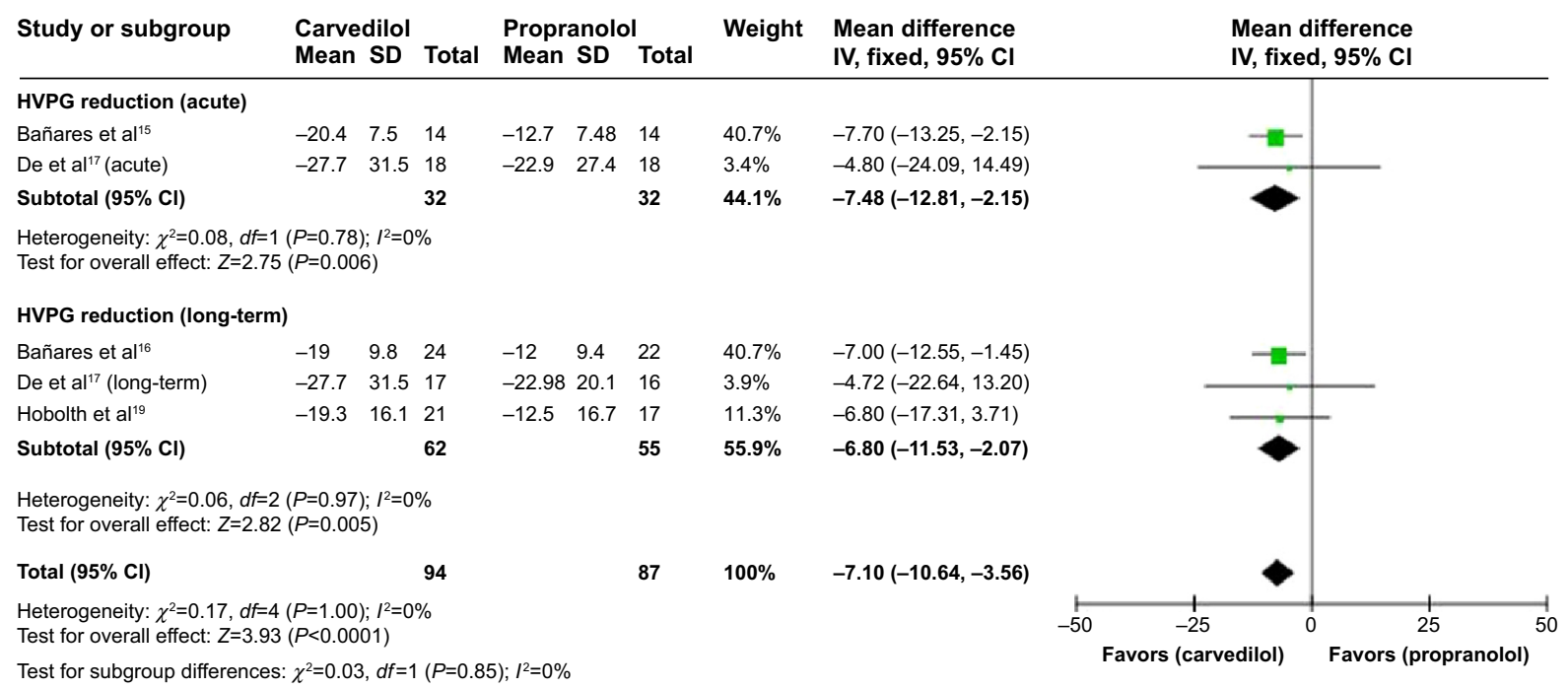

Figure 4 Subgroup analysis (fixed-effect model) of the percentage of hepatic vein pressure gradient reduction.

Notes: Subgroup analysis represents the MDs (rectangles) and $95 \% \mathrm{Cl}$ (horizontal lines) for trials that compared carvedilol and propranolol, excluding three trials with highrisk factor. The size of the rectangles indicates the weight of every trial. The above diamond shows the subtotal $\mathrm{MD}$ and $95 \% \mathrm{Cl}$ of the acute drug administration. The below diamond shows the subtotal MD and $95 \% \mathrm{Cl}$ of the long-term drug administration. The heterogeneity test is also performed.

Abbreviations: MD, mean difference; Cl, confidence interval; SD, standard deviation; IV, inverse variance; HVPG, hepatic vein pressure gradient. 


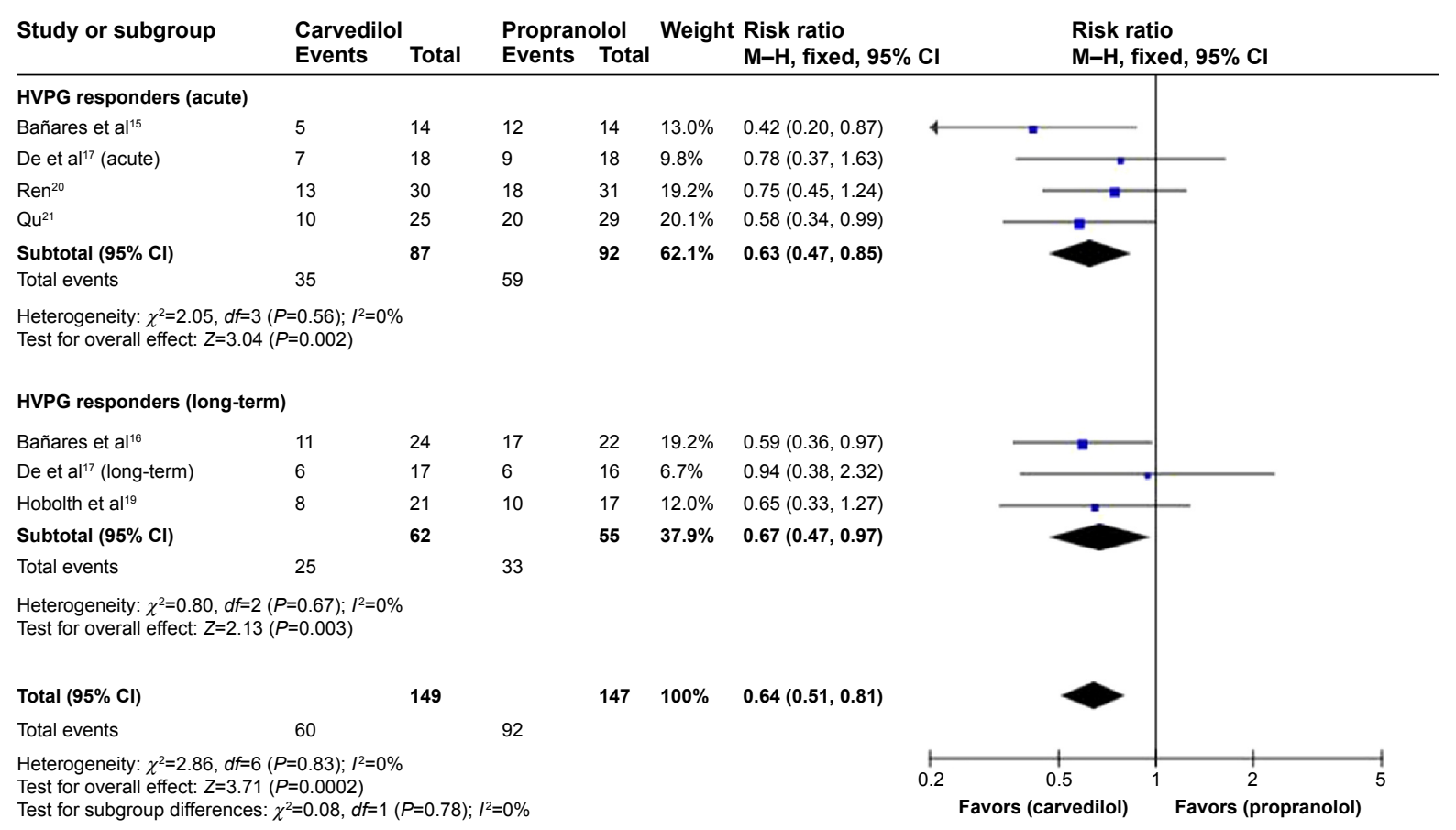

Figure 5 Subgroup analysis (fixed-effect model) of hemodynamic nonresponders, representing the RRs (rectangles) and 95\% Cl (horizontal lines) for trials that compared carvedilol and propranolol.

Notes: The size of the rectangles indicates the weight of every trial. The above diamond shows the subtotal RR and $95 \% \mathrm{Cl}$ of the acute drug administration. The below diamond shows the subtotal RR and $95 \% \mathrm{Cl}$ of the long-term drug administration. The heterogeneity test is also performed.

Abbreviations: RRs, risk ratios; $\mathrm{Cl}$, confidence interval; $\mathrm{M}-\mathrm{H}$, Mantel-Haenszel; $\mathrm{HVPG}$, hepatic vein pressure gradient.

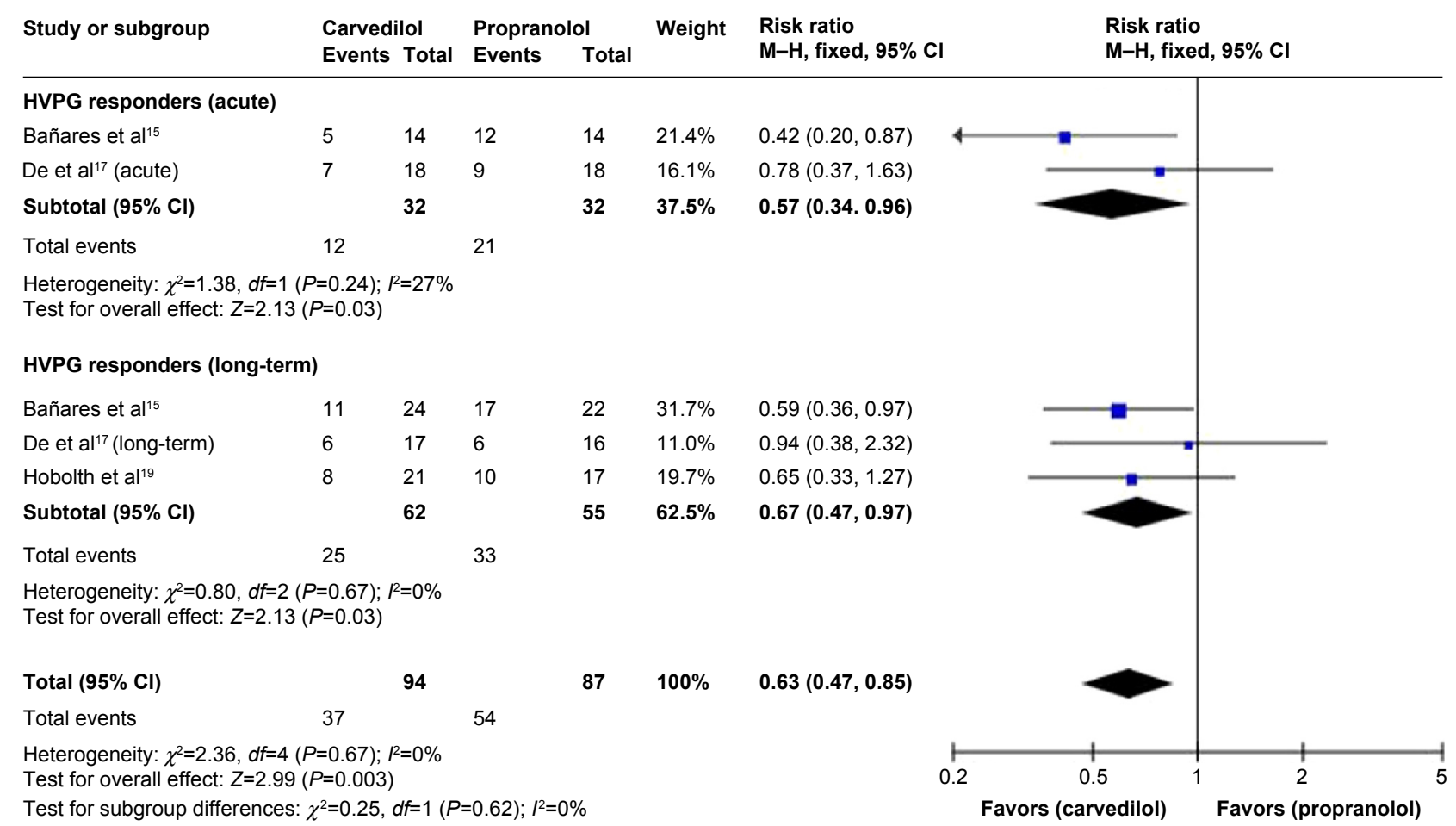

Figure 6 Subgroup analysis (fixed-effect model) of hemodynamic nonresponders.

Notes: Subgroup analysis represents the RRs (rectangles) and $95 \% \mathrm{Cl}$ (horizontal lines) for trials that compared carvedilol and propranolol excluding three studies with high-risk factor. The size of the rectangles indicates the weight of every trial. The above diamond shows the subtotal RR and $95 \% \mathrm{Cl}$ of the acute drug administration. The below diamond shows the subtotal RR and $95 \% \mathrm{Cl}$ of the long-term drug administration. The heterogeneity test is also performed.

Abbreviations: RRs, risk ratios; $\mathrm{Cl}$, confidence interval; M-H, Mantel-Haenszel; HVPG, hepatic vein pressure gradient. 
Table 5 \%MAP reduction of the included studies

\begin{tabular}{|c|c|c|c|c|c|}
\hline & \multirow{2}{*}{$\begin{array}{l}\text { Time of } \\
\text { outcome } \\
\text { assessment }\end{array}$} & \multicolumn{2}{|l|}{ Carvedilol } & \multicolumn{2}{|l|}{ Propranolol } \\
\hline & & $\begin{array}{l}\text { MAP baseline, } \\
\mathbf{m m H g}\left(\text { mean } \pm \mathbf{S D}^{\mathrm{a}}\right)\end{array}$ & $\begin{array}{l}\text { \%MAP reduction } \\
\left(\text { mean } \pm \mathbf{S D}^{\mathrm{a}}\right)\end{array}$ & $\begin{array}{l}\text { MAP baseline, } \\
\left.\text { mmHg (mean } \pm \mathbf{S D}^{\mathrm{a}}\right)\end{array}$ & $\begin{array}{l}\text { \%MAP reduction } \\
\left(\text { mean } \pm \mathbf{S D}^{\mathrm{a}}\right)\end{array}$ \\
\hline Bañares et $\mathrm{al}^{15}$ & Acute & $89 \pm 4$ & $17.2 \pm 2.4$ & $87 \pm 3$ & $3.4 \pm 2.3$ \\
\hline Lin et a $\left.\right|^{18}$ & Acute & $95 \pm 4$ & $11.3 \pm 2.9$ & $94 \pm 3$ & $8.9 \pm 2.2$ \\
\hline $\operatorname{Ren}^{20}$ & Acute & $95.14 \pm 12.02$ & $10.06 \pm 8.73$ & $92.48 \pm 15.88$ & $6.46 \pm 12.56$ \\
\hline $\mathrm{Qu}^{21}$ & Acute & $93.65 \pm 13.16$ & $9.09 \pm 8.65$ & $90.41 \pm 17.02$ & $3.63 \pm 15.76$ \\
\hline \multirow[t]{2}{*}{ De et $\mathrm{al}^{17}$} & Acute & $97.30 \pm 10.25$ & NM & $91.90 \pm 16.03$ & NM \\
\hline & Long-term & $97.30 \pm 10.25$ & NM & $91.90 \pm 16.03$ & NM \\
\hline Bañares et $\mathrm{al}^{16}$ & Long-term & $91.4 \pm 2.5$ & $\mid I \pm I$ & $88.6 \pm 4.5$ & $5 \pm 3$ \\
\hline Hobolth et al ${ }^{19}$ & Long-term & $97 \pm 13$ & $5.1 \pm 14.9$ & $98 \pm 8$ & $8.2 \pm 12.5$ \\
\hline
\end{tabular}

Notes: ${ }^{\text {In }}$ the studies by Bañares et al15,16 and by Lin et $a^{18}$ the standard deviation of the mean was derived from the standard error of the mean reported in the original studies.

Abbreviations: MAP, mean arterial pressure reduction; SD, standard deviation; NM, not mentioned.

has been proved to decrease portal pressure both by lowering the portal blood flow (beta-blocker effect) and by decreasing the hepatic vascular resistance (alpha1-adrenergic blocker effect). As such, carvedilol has the potential to achieve greater reduction of portal pressure than the propranolol. . $^{10,25,26}$ However, some earlier observations ${ }^{15,16,27}$ demonstrated that carvedilol significantly decreased the MAP compared to baseline values and/or compared to propranolol-treated patients, leading to concerns over the use of this drug for long-term administration in patients with portal hypertension. The present meta-analysis of seven studies was conducted to compare the treatment effect on portal hypertension between carvedilol and propranolol and to evaluate the \%MAP reductions caused by the two drugs.
Across all included trials, patients recruited in the two groups were comparable without pronounced differences regarding the number of patients, mean age, sex, etiology of cirrhosis, Child-Pugh score, and history of previous variceal bleeding.

The current meta-analysis reflects that in the available RCTs focusing on carvedilol and propranolol for the prevention of variceal bleeding in patients with portal hypertension, carvedilol reduces HVPG significantly more than propranolol, regardless of acute or long-term drug administration. The pooled MD of \%HVPG reduction achieved by two drugs was -8.62 (CI $-11.76,-5.48)$, favoring carvedilol. No heterogeneity was found. When attention was paid to the subgroups, the figures for acute and long-term drug

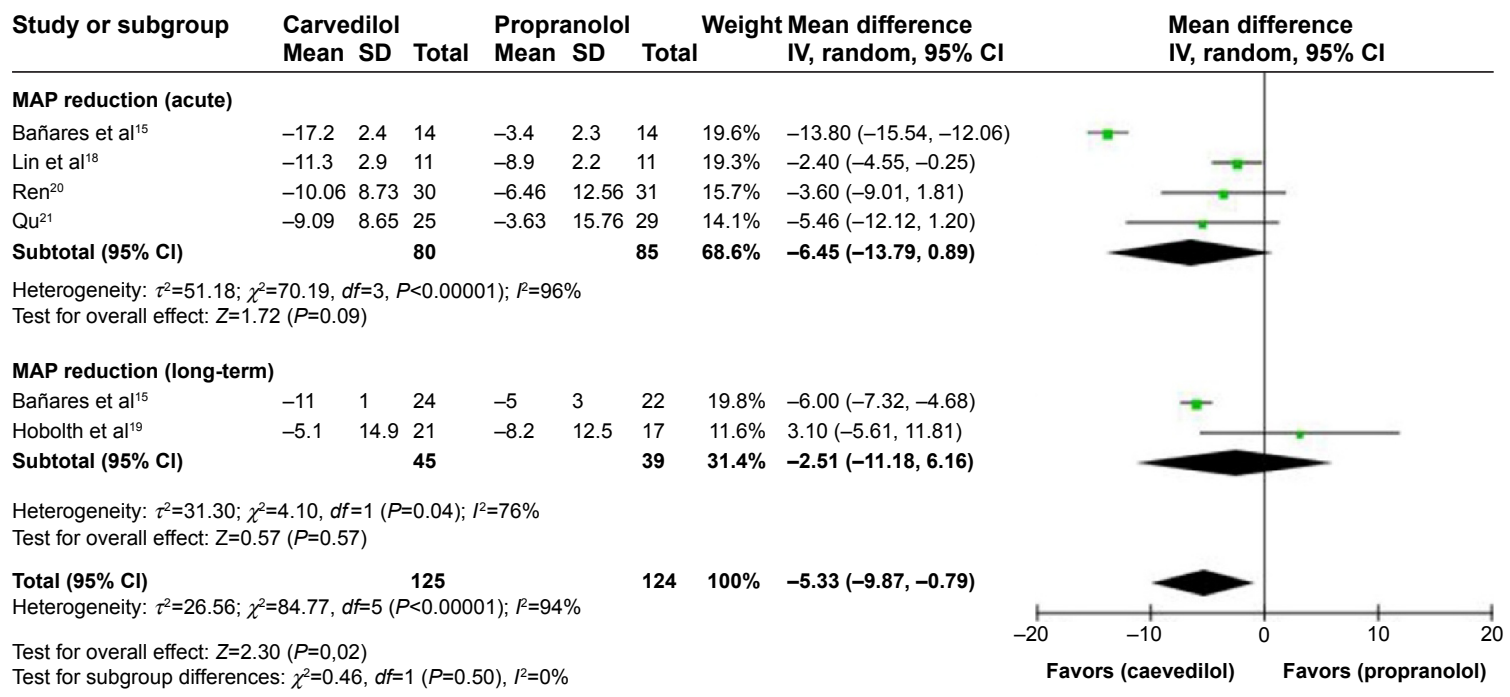

Figure 7 Subgroup analysis (random-effect model) of the percentage of mean arterial pressure reduction, representing the MDs (rectangles) and $95 \% \mathrm{Cl}$ (horizontal lines) for trials that compared carvedilol and propranolol.

Notes: The size of the rectangles indicates the weight of every trial. The above diamond shows the subtotal $\mathrm{MD}$ and $95 \% \mathrm{Cl}$ of the acute drug administration. The below diamond shows the subtotal MD and $95 \% \mathrm{Cl}$ of the long-term drug administration. The heterogeneity test is also performed.

Abbreviations: MD, mean difference; Cl, confidence interval; SD, standard deviation; IV, inverse variance; MAP, mean arterial pressure reduction. 


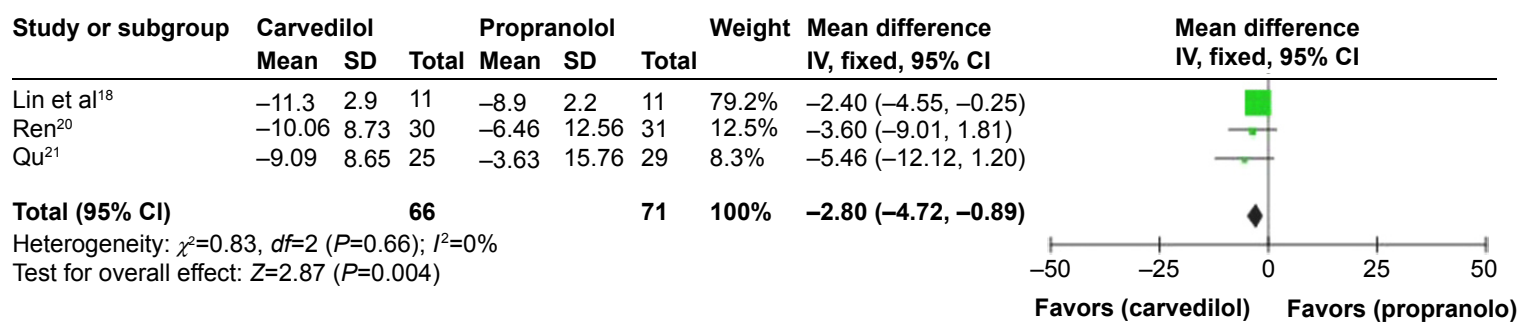

Figure $8 \mathrm{MD}$ (fixed-effect model) of the percentage of mean arterial pressure reduction (\%MAP reduction) between carvedilol and propranolol in acute treatment trials, excluding one study with unclear risk. The heterogeneity test is also performed.

Abbreviations: MD, mean difference; MAP, mean arterial pressure; SD, standard deviation; IV, inverse variance; Cl, confidence interval.

administration were $-10.05(\mathrm{CI}-14.24,-5.86)$ and -6.80 (CI-11.53,-2.07), respectively. The results were consistent with the principal assessment.

With regard to the number of hemodynamic responders, an Austria research conducted by Reiberger et $\mathrm{al}^{28}$ claimed that carvedilol demonstrated great efficacy in the proportion of hemodynamic responders, which was also the case in the current review. In our meta-analysis, the number of patients achieving a reduction in HVPG to $\geq 20 \%$ or to $\leq 12 \mathrm{mmHg}$ was reported in six out of the seven studies (carvedilol: 89/149 vs propranolol: 55/147). The pooled RR of hemodynamic nonresponders reached statistical significance with carvedilol at 0.64 (CI 0.51-0.81; fixed-effect model), denoting superiority of carvedilol in hemodynamic response. The subgroup results, 0.63 (CI 0.47-0.85) and 0.67 (CI 0.47-0.97) for acute and long-term drug administration, respectively, were assessed in accordance with the overall evaluation. However, the results were inconsistent with a previous metaanalysis study ${ }^{29}$ published in early 2014 .

As for the \%MAP reduction, significant heterogeneity $\left(P<0.1, I^{2}=92 \%\right)$ existed between the two treatment groups, hampering evaluation of a pooled effect. No significant difference could be observed in the \%MAP reduction between two drugs across all trials as was shown by the poor overlapping CI boundaries in our study, indicating that carvedilol and propranolol had similar effects in MAP reduction.

Interestingly, when the source of the heterogeneity was explored, we found that if one study ${ }^{15}$ with unclear risk was excluded in the acute assessment, the heterogeneity would be eliminated $\left(P>0.1, I^{2}=0 \%\right)$, suggesting that carvedilol decreased MAP in a more pronounced fashion than propranolol when administered acutely. However, the remaining three studies reviewed were all high-risk trials. Therefore, this result might conceivably be considered as a type I error.

Nevertheless, this difference was clinically meaningful. One patient with symptomatic hypotension ${ }^{17}$ over 90 minutes (recovered over the next 2 days with conservative therapy) was reported in the carvedilol group and two (necessitating cessation of treatment) in the propranolol group. A total of 15 patients developed orthostatic hypotension out of 77 patients treated by carvedilol, compared to nine out of 73 treated by propranolol $(P=0.27>0.05$, Fisher's exact test $)$ in three ${ }^{16,19}$ out of the seven studies.

A final attention was paid to bias. We may have not included all trials comparing carvedilol and propranolol, particularly, those with negative results had been performed but not published. On the other hand, the small number of available studies and their small sample sizes precluded the achievement of a convincing estimation. Furthermore, from the results of the methodological quality assessment, high-risk factors existed in three included studies $^{18}$ with one ${ }^{15}$ incorporating unclear risk, making selection bias, performance bias, and reporting bias possible (Figure 2).

\section{Conclusion}

In conclusion, this meta-analysis of the existing controlled trials suggests that carvedilol reduces HVPG significantly more than propranolol, irrespective of acute or long-term drug administration. The number of hemodynamic responders is significantly higher with carvedilol treatment, and this is supported by a recent study ${ }^{28}$ confirming that carvedilol leads to a significantly greater reduction in HVPG than propranolol and is a rescue treatment for hemodynamic nonresponders to propranolol. However, conclusion that carvedilol reduces MAP more than propranolol cannot be drawn from the data in our meta-analysis. The finding that the acute administration of carvedilol decreased MAP to a greater extent than propranolol did should be viewed with caution. On the basis of the present study, carvedilol is shown to be more effective than propranolol regarding the effect of portal hypertension in patients with cirrhosis. Further comparative trials of carvedilol and propranolol are encouraged to identify the effect of the MAP. 
The current meta-analysis suggests that carvedilol might be recommended for the reduction of portal hypertension in patients. ${ }^{28}$ However, the MAP should be monitored.

\section{Disclosure}

The authors report no conflicts of interest in this work.

\section{References}

1. Villanueva C, Piqueras M, Aracil C. A randomized controlled trial comparing ligation and sclerotherapy as emergency endoscopic treatment added to somatostatin in acute variceal bleeding. $J$ Hepatol. 2006;45: $560-567$.

2. Augustin S, Altamirano J, González A, et al. Effectiveness of combined pharmacologic and ligation therapy in high-risk patients with acute esophageal variceal bleeding. Am J Gastroenterol. 2011;106: $1787-1795$.

3. Abraldes JG, Villanueva C, Bañares R, et al; Cooperative Group for Portal Hypertension and Variceal Bleeding. Hepatic venous pressure gradient and prognosis in patients with acute variceal bleeding treated with pharmacologic and endoscopic therapy. J Hepatol. 2008; 48:229-236.

4. Bosch J, Abraldes JG, Berzigotti A, Garcia-Pagan JC. The clinical use of HVPG measurements in chronic liver disease. Nat Rev Gastroenterol Hepatology. 2009;6:573-582.

5. Groszmann RJ, Garcia-Tsao G, Bosch J, et al; Portal Hypertension Collaborative Group. Beta-blockers to prevent gastroesophageal varices in patients with cirrhosis. N Engl J Med. 2005;353:2254-2261.

6. Bosch J, Garcia-Pagan JC. Prevention of variceal rebleeding. Lancet. 2003;361:952-954.

7. D'Amico G, Garcia-Pagan JC, Luca A, Bosch J. Hepatic vein pressure gradient reduction and prevention of variceal bleeding in cirrhosis: a systematic review. Gastroenterology. 2006;131:1611-1624.

8. Garcia-Tsao G, Sanyal AJ, Grace ND, Carey W. Prevention and management of gastroesophageal varices and variceal hemorrhage in cirrhosis. Hepatology. 2007;46:922-938.

9. Garcia-Tsao G, Bosch J, Groszmann RJ. Portal hypertension and variceal bleeding - unresolved issues. Summary of an American association for the study of liver diseases and European association for the study of the liver single-topic conference. Hepatology. 2008;47:1764-1772.

10. Bosch J. Carvedilol for portal hypertension in patients with cirrhosis. Hepatology. 2010;51:2214-2218.

11. Tripathi D, Ferguson JW, Kochar N, et al. Randomized controlled trial of carvedilol versus variceal band ligation for the prevention of the first variceal bleed. Hepatology. 2009;50:825-833.

12. Lo GH, Chen WC, Wang HM, Yu HC. Randomized, controlled trial of carvedilol versus nadolol plus isosorbide mononitrate for the prevention of variceal rebleeding. J Gastroenterol Hepatol. 2012;27:1681-1687.

13. Shah HA, Azam Z, Rauf J, et al. Carvedilol vs esophageal variceal band ligation in the primary prophylaxis of variceal hemorrhage: a multicentre randomized controlled trial. J Hepatol. 2014;60:757-764.
14. Hobolth L, Bendtsen F, Hansen EF, Moller S. Effects of carvedilol and propranolol on circulatory regulation and oxygenation in cirrhosis: a randomised study. Dig Liver Dis. 2014;46:251-256.

15. Bañares R, Moitinho E, Piqueras B, et al. Carvedilol, a new nonselective beta-blocker with intrinsic anti-alpha1-adrenergic activity, has a greater portal hypotensive effect than propranolol in patients with cirrhosis. Hepatology. 1999;30:79-83.

16. Bañares R, Moitinho E, Matilla A, et al. Randomized comparison of long-term carvedilol and propranolol administration in the treatment of portal hypertension in cirrhosis. Hepatology. 2002;36:1367-1373.

17. De BK, Das D, Sen S, et al. Acute and 7-day portal pressure response to carvedilol and propranolol in cirrhotics. J Gastroenterol Hepatol. 2002; 17:183-189.

18. Lin HC, Yang YY, Hou MC, Huang YT, Lee FY, Lee SD. Acute administration of carvedilol is more effective than propranolol plus isosorbide-5-mononitrate in the reduction of portal pressure in patients with viral cirrhosis. Am J Gastroenterol. 2004;99:1953-1958.

19. Hobolth L, Moller S, Gronbaek H, Roelsgaard K, Bendtsen F, Feldager Hansen E. Carvedilol or propranolol in portal hypertension? A randomized comparison. Scand J Gastroenterol. 2012;47:467-474.

20. Ren RR. The comparison of recent curative effect on the reduction of hepatic vein pressure gradient in patients with cirrhosis. Shandong University. 2012.

21. Qu CX. The preliminary research of the short-term reduction of hepatic vein pressure gradient to predict the long-term curative effect of beta-blockers. Shandong University. 2012.

22. Gluud LL. Bias in clinical intervention research. Am J Epidemiol. 2006;163:493-501.

23. Kjaergard LL, Villumsen J, Gluud C. Reported methodologic quality and discrepancies between large and small randomized trials in metaanalyses. Ann Intern Med. 2001;135:982-989.

24. Garcia-Tsao G. Current management of the complications of cirrhosis and portal hypertension: variceal hemorrhage, ascites, and spontaneous bacterial peritonitis. Gastroenterology. 2001;120:726-748.

25. Tsochatzis EA, Triantos CK, Burroughs AK. Gastrointestinal bleeding: carvedilol-the best beta-blocker for primary prophylaxis? Nat Rev Gastroenterol Hepatol. 2009;6:692-694.

26. Hemstreet BA. Evaluation of carvedilol for the treatment of portal hypertension. Pharmacotherapy. 2004;24:94-104.

27. Tripathi D, Therapondos G, Lui HF, Stanley AJ, Hayes PC. Haemodynamic effects of acute and chronic administration of low-dose carvedilol, a vasodilating beta-blocker, in patients with cirrhosis and portal hypertension. Aliment Pharmacol Ther. 2002;16:373-380.

28. Reiberger T, Ulbrich G, Ferlitsch A, et al; Vienna Hepatic Hemodynamic Lab. Carvedilol for primary prophylaxis of variceal bleeding in cirrhotic patients with haemodynamic non-response to propranolol. Gut. 2013;62:1634-1641.

29. Sinagra E, Perricone G, D’Amico M, Tine F, D’Amico G. Systematic review with meta-analysis: the haemodynamic effects of carvedilol compared with propranolol for portal hypertension in cirrhosis. Aliment Pharmacol Ther. 2014;39:557-568.
Patient Preference and Adherence

\section{Publish your work in this journal}

Patient Preference and Adherence is an international, peer-reviewed, open access journal that focuses on the growing importance of patient preference and adherence throughout the therapeutic continuum. Patient satisfaction, acceptability, quality of life, compliance, persistence and their role in developing new therapeutic modalities and compounds to optimize

\section{Dovepress}

clinical outcomes for existing disease states are major areas of interest for the journal. This journal has been accepted for indexing on PubMed Central. The manuscript management system is completely online and includes a very quick and fair peer-review system, which is all easy to use. Visit http://www. dovepress.com/testimonials.php to read real quotes from published authors. 